\title{
Las medidas cautelares en los juicios laborales
}

\section{Precautionary measures in labor lawsuits}

\author{
Ignacio Barcos-Arias \\ ub.ignaciobarcos@uniandes.edu.ec \\ Universidad Regional Autónoma de los Andes, Babahoyo \\ Ecuador \\ https://orcid.org/0000-0003-2779-5512 \\ María José Caicedo-Parrales \\ caicedomajo2@gmail.com \\ Universidad Regional Autónoma de los Andes, Babahoyo \\ Ecuador \\ https://orcid.org/0000-0003-4529-2126 \\ Marlon Javier Espinoza-Campbell \\ marlonespinoza846@gmail.com \\ Universidad Regional Autónoma de los Andes, Babahoyo \\ Ecuador \\ https://orcid.org/0000-0001-6706-1295
}

Recepción: 15 de septiembre 2021

Revisado: 25 octubre 2021

Aprobación: 15 de noviembre 2021

Publicación: 01 de diciembre 2021 


\section{Estimado Editor (a):}

En el ejercicio profesional es muy común examinar que los trabajadores luego de haber entablado una contienda legal no puedan hacer efectivos los derechos que lograron mediante sentencia. La misma Constitución (2008) en su artículo 33 declara que:

El trabajo es un derecho y un deber social, y un derecho económico, fuente de realización personal y base de la economía.

El Estado garantizará a las personas trabajadoras el pleno respeto a su dignidad, una vida decorosa, remuneraciones y retribuciones justas y el desempeño de un trabajo saludable y libremente escogido o aceptado, al enunciar este artículo el Estado se convierte en garantista y defensor de los derechos de los trabajadores y no solo se limita a la aplicación de las normas ya establecidas, sino al establecimiento de legislación efectiva que proteja a la clase obrera que es la más débil en una relación laboral. Se deduce, por tanto, que la problemática tiene importancia y trascendencia social y jurídica para ser investigada, en procura de medios alternativos de carácter jurídico-penal que la prevengan y controlen en sus manifestaciones. (Atencio González, et al. 2020).

Desde la época del principio de la humanidad el trabajo ha sido la fuerza de producción por medio de la cual se da la modificación de los productos y es la energía que pone en funcionamiento los medios de producción. Se le ha dado múltiples definiciones de las cuales citaré, en primer lugar, de la que da Cabanellas (2006), en su Diccionario Jurídico Elemental, el cual manifiesta, que el trabajo es: "El esfuerzo humano, físico o intelectual, aplicado a la producción u obtención de la riqueza. Toda actividad susceptible de valoración económica por la tarea, el tiempo o el rendimiento. Ocupación de conveniencia social o individual, dentro de la licitud. En tal sentido, se define al trabajo como el esfuerzo humano que se dedica a la transformación o producción de elementos que acrecientan el patrimonio ya sea personal o colectivo. (Morris, 2004).

Así mismo, acorde a lo que dispone, el Código del Trabajo (2005), en su Art. 1 señala que: Los conceptos de este Código regulan las relaciones entre empleadores y 
trabajadores y se aplican a las diversas modalidades y condiciones de trabajo. Las normas relativas al trabajo contenidas en leyes o en convenios internacionales ratificados por el Ecuador, serán aplicadas en los casos específicos a los que ellos se refieren, ahora bien, los trabajadores para requerir el respeto de sus derechos, constantes en la Ley, pueden asistir a la Administración de Justicia, que pueden ser los Juzgados de Trabajo y Tribunales de Conciliación y Arbitraje, la Corte Nacional de Justicia y las Cortes Provinciales de Justicia del Ecuador. De esta forma los jueces de trabajo ejercen jurisdicción y competencia en el, conocimiento y en la resolución de conflictos individuales derivados de relaciones de trabajo, y que no encuentren sometidos al conocimiento de otra actividad.

De manera común se manifiesta que la solicitud de medidas cautelares luego de la sentencia favorable de primera instancia no protege eficazmente los derechos del trabajador, basan su criterio en el hecho de que toda persona en su fuero interno conoce si ha cumplido o no cabalmente sus obligaciones de cualquiera sea el tipo, mucho más en el aspecto laboral, entonces resulta relativamente sencillo inferir, el resultado favorable o desfavorable de una contienda, y hay mucho tiempo como para que el empleador oculte sus bienes, los enajene, entre otros.

Por lo tanto, en ningún momento el artículo 594 del Código del Trabajo está poniendo obstáculos a los principios del debido proceso ni del sistema procesal, para alcanzar la justicia en una reclamación laboral; está en armonía porque la Ley Especial, tiene mayor fuerza obligatoria, y los derechos laborales son irreductibles; que los derechos son irreversibles, y, que si se cumple con las leyes propuestas.

En este sentido, en materia de protección de derechos es difícil encontrar un punto medio entre la justicia y el extremado proteccionismo, el cual se acusa dependiendo de la situación en la que nos encontremos, en el caso de abogados, deberemos defender a grupos de trabajadores, así como de empleadores, y desde ambos bandos siempre se vislumbra vacíos en la ley. En todo caso nuestra legislación muestra grandes avances en protección a los trabajadores, herramientas con las cuales ya se puede luchar, pero de todos modos este sistema debe ser fortalecido para que garantice la tutela y seguridad jurídica. 
Por lo tanto, las medidas cautelares no son aún una herramienta jurídica que se use comúnmente, ya que el tiempo en el que transcurre entre la demanda y la sentencia de primera instancia, si el demandado tiene a bien disponer de sus bienes para ocultarlos, tiene tiempo más que suficiente para hacerlo; llegada a esta etapa, no resta más que esperar a la resolución de segunda instancia.

El Código de Trabajo ha previsto que el juicio laboral sea muy rápido, y sus principios así lo prescriben, pero yendo a la práctica debido a la carga procesal de los juzgados, un juicio laboral se puede extender hasta seis meses, o más en primera instancia, en el mismo contexto el empleador procura dilatar más el proceso, negándose a la conciliación, mientras tanto ninguna medida asegura al trabajador que de resultar victorioso pueda reclamar su reivindicación, pues una vez que ya tenga la sentencia en sus manos, ejecutoriada, si tal hubiera sido el caso de que se dé un ocultamiento de sus bienes eso devendría en un juicio penal, que de igual forma se extiende mucho tiempo. Se debe tomar en cuenta que el trabajador depende de la fuerza de su trabajo y su remuneración para mantener a su familia, así que el hecho de que tenga una sentencia a su favor y no pueda hacerla efectiva de un modo inmediato, demuestra de que no existe una efectiva protección de los derechos.

Por otro lado, la tutela jurídica, tiene su origen etimológico en tutela que significa cuidar proteger, por lo que esta tutela a mi criterio tiene especial enfoque en la protección de los derechos que se garantizan a los ciudadanos mediante las leyes, y que incluso el Estado los hará viables jurídicamente. Las medidas cautelares deben ser solicitadas a petición de parte, y se debe indicar sobre qué bien o persona recaerá dicha medida, se puede además comenzar a agregar nuevos elementos como el hecho de que si se la dicta en el momento procesal del inicio del juicio se debe tener justificativos que motiven la emisión de dicha medida cautelar. Se debe tomar en cuenta el hecho que, si se dictara medidas cautelares de oficio por parte del juzgador, esto duplicaría los trámites en los juzgados, y el levantarlas después de que finalice el juicio sería otro trámite para seguir.

Por ello, las medidas cautelares tienen como propósito asegurar que un derecho se pueda hacer efectivo luego de que agotado el trámite judicial se declare la existencia 
de tal derecho, y son una importante herramienta en la protección de los derechos de quien pretende un resarcimiento. En el Código de Trabajo de Ecuador, existe un vacío, pues señala la aplicación de medidas cautelares solo después de la sentencia favorable de primera instancia, y hasta que dicha resolución no existe ninguna medida que asegure la efectivización del derecho en litigio.

\section{FINANCIAMIENTO}

No monetario.

\section{AGRADECIMIENTO}

A la Universidad Regional Autónoma de los Andes, Babahoyo, por motivar el desarrollo de la Investigación.

\section{REFERENCIAS CONSULTADAS}

Asamblea Nacional Constituyente de la República del Ecuador, (2008). Constitución de la República del Ecuador. [Constitution of the Republic of Ecuador]. Montecristi. Registro Oficial 449 de 20-oct-2008. Recuperado de https://n9.cl/sia

Asamblea Nacional de la República del Ecuador (2005). Código del Trabajo, Ecuador. [Labor Code, Ecuado]. Registro Oficial Número 167. 16 de diciembre de 2005. Última reforma 20 de abril de 2015. Recuperado de: https://n9.cl/652cf

Atencio González, R. E., Arrias Añez, J. C. D. J., Coronel Piloso, J. E., y Ronquillo Riera, O. I. (2020). El trabajo como hecho social en el ordenamiento jurídico ecuatoriano. Revista Universidad y Sociedad, 12(4), 350-354.Recuperdo de: https://n9.cl/95rkc

Cabanellas, G. (2008). Diccionario Jurídico Elemental. Edición Heliasta.

Morris, W. (2004). Trabajo útil o esfuerzo inútil. Pepitas de calabaza editorial. Logroño. 
Año VI. Vol. VI. N 1 . Edición Especial. 2021

Hecho el depósito de Ley: FA2016000064 ISSN: 2542-3371

FUNDACIÓN KOINONIA (F.K). Santa Ana de Coro, Venezuela

Ignacio Barcos-Arias; María José Caicedo-Parrales; Marlon Javier Espinoza-Campbell

(C2021 por los autores. Este artículo es de acceso abierto y distribuido según los términos y condiciones de la licencia Creative Commons Atribución-NoComercial-Compartirlgual 4.0 Internacional (CC BY-NC-SA 4.0)

(https://creativecommons.org/licenses/by-nc-sa/4.0/) 